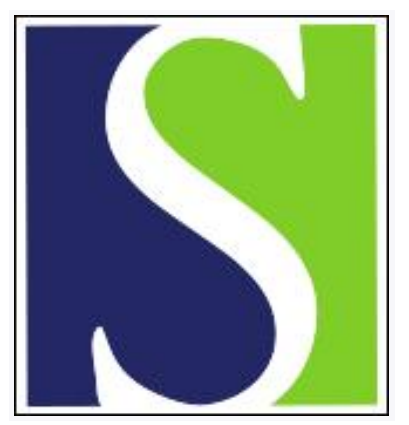

Scand J Work Environ Health 2010;36(3):242-249

https://doi.org/10.5271/sjweh.2911

Published online: 26 Mar 2010, Issue date: 01 May 2010

Modeling the Unites States government's economic cost of noise-induced hearing loss for a military population

by Tufts JB, Weathersby PK, Rodriguez FA

Affiliation: Department of Communication Sciences, University of Connecticut, 850 Bolton Road, Unit 1085, Storrs, CT 06269, USA. jennifer.tufts@uconn.edu

Key terms: ANSI S3.44-1996; compensation; economic cost; economics; hearing conservation program; hearing loss; ISO 1999; military; military population; modeling; noise-induced hearing loss; occupational hazard; population; Unites States; Unites States government; US Navy; veteran; workplace

This article in PubMed: www.ncbi.nlm.nih.gov/pubmed/20339823 


\title{
Modeling the Unites States government's economic cost of noise-induced hearing loss for a military population
}

\author{
by Jennifer B Tufts, PhD, ${ }^{1}$ Paul K Weathersby, PhD, ${ }^{2}$ Francisco A Rodriguez, PhD ${ }^{1}$
}

\begin{abstract}
Tufts JB, Weathersby PK, Rodriguez FA. Modeling the Unites States government's economic cost of noise-induced hearing loss for a military population. Scand J Work Environ Health. 2010;36(3):242-249.

Objective The purpose of this paper is to demonstrate the feasibility and utility of developing economic cost models for noise-induced hearing loss (NIHL). First, we outline an economic model of NIHL for a population of US Navy sailors with an "industrial"-type noise exposure. Next, we describe the effect on NIHL-related cost of varying the two central model inputs - the noise-exposure level and the duration of exposure. Such an analysis can help prioritize promising areas, to which limited resources to reduce NIHL-related costs should be devoted.
\end{abstract}

Methods NIHL-related costs borne by the US government were computed on a yearly basis using a finite element approach that took into account varying levels of susceptibility to NIHL. Predicted hearing thresholds for the population were computed with ANSI S3.44-1996 and then used as the basis for the calculation of NIHL-related costs. Annual and cumulative costs were tracked. Noise-exposure level and duration were systematically varied to determine their effects on the expected lifetime NIHL-related cost of a specific US Navy sailor population.

Results Our nominal noise-exposure case [ $93 \mathrm{~dB}(\mathrm{~A})$ for six years] yielded a total expected lifetime cost of US\$13 472 per sailor, with plausible lower and upper bounds of US\$2500 and US\$26 000. Starting with the nominal case, a decrease of $50 \%$ in exposure level or duration would yield cost savings of approximately $23 \%$ and $19 \%$, respectively. We concluded that a reduction in noise level would be more somewhat more cost-effective than the same percentage reduction in years of exposure.

Conclusion Our economic cost model can be used to estimate the changes in NIHL-related costs that would result from changes in noise-exposure level and/or duration for a single military population. Although the model is limited at present, suggestions are provided for adapting it to civilian populations.

Key terms ANSI S3.44-1996; compensation; hearing conservation program; ISO 1999; military; noise-induced hearing loss; occupational hazard; US Navy; veteran, workplace.

Noise-induced hearing loss (NIHL) is estimated to be the most common occupational disease in the United States (US) (1) and the fourth most common in the European Union (EU), with an incidence of 4.7 per 100000 workers in the EU (2). Worldwide, it is estimated that approximately $16 \%$ of disabling hearing losses are caused by exposure to occupational noise. This percentage is slightly lower (approximately $9 \%$ ) in highly developed regions, including the US and Western Europe (3). Civilian sectors reporting high prevalence of NIHL include manufacturing, construction, agriculture, and mining (2). NIHL has been shown to lead to accidents and injury in the workplace $(4,5)$ and may constitute an operational hazard in the military (6). It is also a financial burden. In fiscal year 2005, disability payments to military veterans with auditory disorders, including NIHL and tinnitus, exceeded US\$1 billion (7). The total cost of NIHL generated by the US military is unknown but probably much higher because of additional NIHL-related costs, such as those attributable to annual monitoring audiometry and the distribution of hearing aids. Currently, hearing protection devices are the primary means by which noise exposure is controlled, albeit with limited success $(8,9)$. The cost of NIHL could potentially be reduced if more effective means of controlling noise exposure were implemented (eg, deploying "quieter" systems in some situations). However, such strategies may involve additional expenditures in the short term. To justify the

1 University of Connecticut, Storrs, Connecticut, United States.

2 Naval Submarine Medical Research Laboratory, Groton, Connecticut, United States.

Correspondence to: Dr J Tufts, Department of Communication Sciences, University of Connecticut, 850 Bolton Road, Unit 1085, Storrs, CT 06269, USA. [E-mail: jennifer.tufts@uconn.edu] 
additional expense, a long-term cost model of NIHL would be useful.

The purpose of this paper is to demonstrate the feasibility and utility of developing a cost model for NIHL. First, we outline an economic model of the costs faced by the US government resulting from NIHL for a population of US Navy sailors. Next, we describe the results of a sensitivity analysis of two factors in our model - equivalent noise-exposure level and the cumulative duration of noise exposure. These are the only factors in our model that affect the prevalence and severity of NIHL; both can be reduced in many cases by engineering or administrative controls. The results of the sensitivity analysis are used to determine where limited financial resources can best be focused to reduce NIHL and its associated costs.

\section{Methods}

We have previously described the development of our NIHL cost model in detail (10). In this paper, we summarize the most salient information in order to demonstrate the feasibility of developing such a model and provide background for our discussion of the sensitivity analysis and possible adaptations of the model.

\section{Model description}

Costs due to NIHL are divided into those incurred during active duty and payable by the US Navy, and those incurred during retirement and payable by the US Department of Veterans Affairs (VA). For each cost factor, there are two elements - the cost itself and the probability that the cost will be triggered. Cost data are primarily for the Baltimore, Maryland area in 2004. They were obtained from official correspondence, websites, and consultation with US Navy and VA officials and audiologists. No discount rate was applied. Probabilities were derived from data in existing military databases and consultations with Navy and VA officials and audiologists. Computations required only addition, multiplication, and logarithms, so the model was fully deterministic (probabilities were treated as fixed fractions). Both EXCEL (Microsoft Corporation, Redmond, MA, USA) and MATLAB (The MathWorks, Natick, MA, USA) were used.

\section{Data sources and probabilities}

In this section, sources of cost data and probabilities are given. Several of the key assumptions in the model are summarized in table 1.

US Navy costs. US Navy costs due to NIHL include those associated with (i) administration and overhead for the Navy hearing-conservation program (HCP), (ii) annual monitoring audiometry, (iii) hearing aids, and (iv) early career reassignment due to hearing loss.

Administration and overhead costs include personnel costs for full-time HCP staff (eg, audiologists and program managers) and the annualized cost of fielding the automated system used by the Navy for audiometric testing and record-keeping. Costs for personnel with part-time HCP-related duties, such as occupationalhealth nurses, were not included; these jobs would be retained even if the HCP were eliminated. The annual HCP administrative and overhead cost per HCP enrollee was calculated at US\$12.21. Because this cost is fixed, its probability of occurrence is $100 \%$.

At least once a year, each HCP enrollee has a monitoring audiogram administered by an audiometric technician. Costs include the audiogram, a year's supply of

Table 1. Assumptions of the noise-induced hearing loss (NIHL) cost model for a military population. See text for details.

\footnotetext{
General assumtions

Cost data are from 2005 for the Baltimore (Maryland) area.

Each US Navy hearing conservation program enrollee receives an annual monitoring audiogram.

Average pay grade for a Navy hearing conservation program enrollee is E-4 (a medium non-officer rank).

All veterans previously enrolled in the Navy hearing conservation program apply for US Department of Vetern Affairs (VA) benefits and undergo a VA compensation and pension exam.

The veteran has 2.18 dependents, whose cost is the average of the costs of the various types of dependent (eg, child, dependent parent, etc.)

The cost of hearing aids and the hearing-threshold-based probability of issuing hearing aids are the same for the VA and the Navy.

If hearing aids are worn, audiological exams and hearing aid checks are repeated annually.

Hearing aids are replaced every five years.

No significant noise exposure occurs outside working hours (while on active duty) or after retirement.

Death occurs at age 77 if the age of 40 is reached.

Specific assumptions to the example population of machinist's mates

Noise exposure in the main machinery room begins at age 20 , following 2 years of training, and ends at age 38 with retirement.

Machinist's mates work in the main machinery room 12 hours per day, 7 days per week, for a total of 6 years (spread over 20 years).

Taking hearing protection and extended workshifts into account, the equivalent exposure level for machinist's mates is $93 \mathrm{~dB}(\mathrm{~A})$.

The NIHL incurred by machinist's mates is binaurally symmetrical.
} 
disposable earplugs, and lost worktime. This last cost was calculated assuming that the average pay grade for an HCP enrollee is E-4 (a medium non-officer rank).

At the time of the annual audiogram, automated software checks for the occurrence of a significant threshold shift (STS). A STS is defined as an average change of $10 \mathrm{~dB}$ or more at the frequencies of 2000,3000 , and $4000 \mathrm{~Hz}$, in either ear, relative to the sailor's baseline audiogram. If an STS occurs, it must be verified with a follow-up audiogram. If the STS is resolved (ie, reverts to baseline STS) at that time, no STS is recorded for that year. If the STS persists, a second follow-up audiogram is performed immediately. Again, if the STS is resolved, no STS is recorded. If the STS persists on the second examination, the sailor may be referred to an audiologist for consultation. Additionally, the sailor's baseline audiogram is reset. The two follow-up audiograms and the audiologist consultation accrue costs for the procedures and the sailor's lost worktime.

Probabilities associated with the annual monitoring audiometry include the sailor's probability of showing up for initial and follow-up appointments and the rates of true and false positive STS. (A false negative STS does not incur costs.) These probabilities were estimated from the results of a data-repository query for the 18-month period, beginning January 2004, and from consultation with Navy and VA officials and audiologists. Table 2 defines these probabilities and gives their estimated values. Table 3 lists the steps associated with annual monitoring audiometry and their associated probabilities and costs; it also provides a calculation of the expected cost of annual monitoring audiometry. As table 3 shows, the total annual per-enrollee cost of monitoring audiometry depends upon whether or not the enrollee incurs an STS.

To calculate costs associated with the prescription of hearing aids to active-duty sailors, we assumed the following steps: (i) an initial audiological examina- tion is performed to determine hearing aid candidacy; (ii) hearing aids are selected, issued, and evaluated; (iii) audiological exams and hearing aid checks are repeated annually; (iv) the sailor receives a supply of batteries; and (v) the hearing aids are replaced on average every five years. The annual cost of these steps, averaged over the five-year life of the hearing aids, was calculated at US\$440.03.

Hearing aid candidacy is based on multiple considerations, not just hearing-threshold levels; however, thresholds are a primary consideration, and other decision factors are considerably more complicated to model. The military audiologists we consulted provided a threshold-based decision criterion for issuing hearing aids. For hearing threshold levels at 1000, 2000, 3000, and $4000 \mathrm{~Hz}$, determine $\mathrm{L}$ - the highest average of any two adjacent frequencies. If $\mathrm{L}=30 \mathrm{~dB}$ hearing level (HL), the probability of issuing hearing aids is $15 \%$. This probability doubles for every $10 \mathrm{~dB}$ increase in $\mathrm{L}$, with $100 \%$ probability reached at $\mathrm{L}=58 \mathrm{~dB} \mathrm{HL}$.

Most training costs occur relatively early in a sailor's career. The average annual training cost is equal to the total training cost amortized over the average tenure in that occupational specialty. If a sailor accrues sufficient hearing loss, he/she may no longer meet minimum audiometric standards for his/her occupational specialty and may be reassigned. This disqualified sailor's annual training cost is higher than that of the average sailor, because his/her tenure is shorter than average. The excess retraining cost averaged over all of the sailors in our example population (see example population section) was US\$1378, but we did not include that in the total since general practice is to waive the disqualification.

VA costs. We assumed that upon retirement, all veterans previously enrolled in the Navy HCP apply for VA benefits and undergo an audiology compensation and

Table 2. Rates and probabilities associated with US Navy annual monitoring audiometry. Table adapted from Sachs et al, 2007 (10). $[r$ = rate; comp = compliance; $p=$ probability; STS = standard threshold shift; $f / u p=$ follow-up; aud consult = audiologist consultation ]

\begin{tabular}{|c|c|c|}
\hline Rate or probability & Definition & Estimated value \\
\hline r(comp) & Rate of sailor compliance with annual audiometry & $0.72^{\mathrm{a}}$ \\
\hline $\mathrm{p}$ (true STS) & Probability of a true STS in annual audiogram & Either 0 or 1 in a given year ${ }^{b}$ \\
\hline r(false STS) & Rate of false positive STS in annual audiogram & $0.13^{a}$ \\
\hline r(f/up no-show) & Rate of sailor no-shows for first follow-up audiogram, if indicated & $0.60^{a}$ \\
\hline r(need second f/up) & Rate of need for second follow-up audiogram & $0.60^{a, c}$ \\
\hline r(aud consult) & Rate of audiologist consult for unresolved STS & $0.50^{d}$ \\
\hline
\end{tabular}

a From Defense Occupational and Environmental Health Readiness System - Hearing Conservation (DOEHRS-HC) data repository query for 18-month period beginning January 2004.

b The computation cycle for the model is one year. Presence/absence of STS depends on the predicted hearing loss for that year from ANSI S3.44-1996

(11). Thus, for a given individual, p(true STS) is either 0 or 1 for any given year.

c Typically, the second follow-up audiogram occurs immediately after the first, if the first does not resolve the STS. We assumed that every sailor who

needs the second follow-up audiogram obtains it if he/she is present for the first follow-up.

d From consultation with military audiologists. 
Table 3. Expected annual cost of monitoring audiometry. Table adapted from Sachs et al, 2007 (10). Small apparent errors in the cost figures are due to rounding. From table 2 , footnote $b, p$ (true STS) is either 0 or 1 . [ $r=$ rate; comp $=$ compliance; $p=p$ probability; STS = standard threshold shift; f/up = follow-up; aud consult = audiologist consultation]

\begin{tabular}{|c|c|c|c|c|c|}
\hline \multirow[t]{2}{*}{ Item } & \multirow[t]{2}{*}{ Associated probability } & \multirow[t]{2}{*}{ Probability value } & \multirow[t]{2}{*}{$\begin{array}{l}\text { Item cost } \\
\quad(\text { US\$) }\end{array}$} & \multicolumn{2}{|c|}{$\begin{array}{l}\text { Expected annual } \\
\text { cost }(\$)\end{array}$} \\
\hline & & & & $\begin{array}{l}\text { with } \\
\text { STS }\end{array}$ & $\begin{array}{l}\text { without } \\
\text { STS }\end{array}$ \\
\hline Annual monitoring audiogram & r(comp) & 0.72 & $91.25^{\mathrm{a}}$ & 65.70 & 65.70 \\
\hline $\begin{array}{l}\text { Is an STS observed? (Triggers } \\
\text { follow-up testing) }\end{array}$ & $r($ comp $) \times[p($ true STS $)+r($ false STS $)]$ & $\begin{array}{l}0.72 \times[p(\text { true } S T S)+0.13] \\
=\text { either } 0.09 \text { or } 0.81\end{array}$ & none & none & none \\
\hline $\begin{array}{l}\text { Did sailor show up for first follow- } \\
\text { up audiogram, if indicated? }\end{array}$ & $\begin{array}{l}{[1-r(f / \text { up no-show })] \times r(\text { comp }) \times[p(\text { true STS })} \\
+r(\text { false STS })]\end{array}$ & $\begin{array}{l}0.40 \times 0.72 \times[p(\text { true STS }) \\
+0.13]=\text { either } 0.04 \text { or } 0.33\end{array}$ & $63.96^{b}$ & 20.82 & 2.39 \\
\hline $\begin{array}{l}\text { Did the sailor have a second } \\
\text { follow-up audiogram, if indicated? }\end{array}$ & $\begin{array}{l}r(\text { need second f/up }) \times[1-r(\text { f/up no-show })] \times \\
r(\text { comp }) \times[p(\text { true STS })+r(\text { false STS })]\end{array}$ & $\begin{array}{l}0.60 \times 0.40 \times 0.72 \times \\
{[p(\text { true STS })+0.13]} \\
=\text { either } 0.022 \text { or } 0.195\end{array}$ & $19.08^{c}$ & 3.73 & 0.43 \\
\hline Did STS persist? & $r($ comp $) \times p($ true STS $)$ & $\begin{array}{l}0.72 \times p(\text { true STS }) \\
=\text { either } 0 \text { or } 0.72\end{array}$ & none & none & none \\
\hline $\begin{array}{l}\text { Was sailor referred to audiologist } \\
\text { on the basis of a persistent STS? }\end{array}$ & $r($ comp $) \times p($ true STS $) \times r($ aud consult $)$ & $\begin{array}{l}0.72 \times p(\text { true } S T S) \times 0.50 \\
=\text { either } 0 \text { or } 0.36\end{array}$ & $58.91^{d}$ & 21.21 & 0 \\
\hline \multicolumn{3}{|l|}{$\begin{array}{l}\text { Total expected cost for annual } \\
\text { monitoring audiometry per sailor (US\$) }\end{array}$} & & 111.46 & 68.52 \\
\hline
\end{tabular}

pension (audio C\&P) examination with a one-time cost of US\$110.00. Depending on the results of the audio C\&P examination, hearing-related VA benefits may or may not ensue. Other VA costs related to NIHL include those associated with VA administration and overhead, hearing aids, and disability compensation.

VA overhead was estimated as the administrative fraction of the direct costs summarized in the VA 2005 performance and accountability report (12). The rate was $39.2 \%$ for medical benefits and $4.1 \%$ for compensation payments.

VA-specific cost information on hearing-aid benefits was unavailable. The annual cost of hearing aids and the hearing-threshold-based probability of issuing hearing aids were adopted from the Navy model.

To be eligible for disability benefits (either at retirement or at a future time if hearing loss worsens), the veteran's hearing loss at the time of his/her departure from the military must be "as likely as not" related to military service, as determined by the VA. For the model, we adopted the following criterion as a substitute for the VA's "as likely as not" determination: a veteran is potentially eligible for disability benefits only if he/she incurred an STS while on active duty. The rationale for this simplification is that the STS can be considered objective evidence of NIHL sustained during service.

Compensation does not automatically ensue even if the hearing loss is connected to service. Instead, com- pensation is based primarily on the percentage of disability, which is a somewhat arbitrary quantity that takes into account hearing-threshold levels, word-recognition scores, and asymmetry of loss. The VA provides guidelines for cases in which only hearing threshold levels are available (as in our model). Since the noise exposure for our chosen population (see next section) is steadystate (ie, constant) and relatively omni-directional, we assumed symmetrical hearing loss. (Compensation for asymmetrical hearing loss would likely be lower.)

The amount of compensation is also affected by complex VA policies that were not included in the model because they tend to offset one another and may not add much to the utility of the model. These include policies regarding the sailor's number and type of dependents, combat-related compensation, more than one disability type, and care-giving responsibilities for a spouse. Our model assumes 2.18 dependents (13), whose cost is the average of the costs of the various types of dependent (eg, child, dependent parent). Table 4 lists percentages of disability, associated hearing loss ranges, and the monthly cost of disability compensation (all figures from 2004), taking these simplifying caveats into account. Compensation benefits are paid until the veteran dies. It should be noted that the cost of disability compensation to the government is somewhat reduced by VA policies (in force in 2005) regarding concurrent retirement and compensation pay, and in many cases will 
Table 4. Simplified cost of veterans' disability compensation for hearing loss. Assumes 2.18 dependents. Table adapted from Sachs et al, 2007 (10). [HL = hearing loss]

\begin{tabular}{lrrrrrrrrrr}
\hline & \multicolumn{10}{c}{ Disability (\%) } \\
\cline { 2 - 11 } & \multicolumn{1}{c}{0} & \multicolumn{1}{c}{10} & 20 & 30 & 40 & 50 & 60 & 80 & 100 \\
\cline { 2 - 10 } & Average dB(HL) at 1000, 2000, 3000, and $4000 \mathrm{~Hz}$ & $<56$ & $56-62$ & $63-69$ & $70-77$ & $78-83$ & $84-90$ & $91-97$ & $98-104$ & $\geq 105$ \\
Cost per month (US\$) & 0 & 108 & 210 & 389 & 553 & 772 & 970 & 1402 & 2407 \\
\hline
\end{tabular}

not equal the amounts presented in table 4 . These cost offsets were taken into account in the model.

\section{Example population}

To illustrate our model, we identified an occupational specialty within the US Navy for which noise exposure is fairly predictable, namely, specially trained machinist's mates working in the main machinery room of Nimitzclass aircraft carriers. Machinery room noise is broadband and relatively steady-state. The "typical" career machinist's mate works in the main machinery room seven days per week, 12 hours per day, for an estimated six years in total. This shipboard noise exposure is spread over a 20 -year career, and is weighted more heavily in the early years of the machinist's mate's career. From previous work $(14,15)$, we estimated the equivalent exposure level of the machinist's mates, taking the wearing of hearing protection into account, to be $93 \mathrm{~dB}(\mathrm{~A})$ [corresponding to exposure to $90 \mathrm{~dB}(\mathrm{~A})$ for 84 hours per week].

\section{Modeling noise-induced hearing loss}

Predicted rate and severity of hearing loss in the machinist's mates was calculated according to the American National Standards Institute (ANSI) determination of occupational noise exposure and estimation of noise-induced hearing impairment: S3.44-1996 (11). ANSI S3.44-1996, adapted almost verbatim from the International Organization for Standardization (ISO) 1999 acoustics standard (16), provides algorithms for calculating: (i) probability distributions of predicted noise-induced permanent threshold shifts, (ii) predicted hearing thresholds associated with age, and (iii) predicted hearing thresholds associated with both age and noise exposure. The input variables required by the ANSI algorithms are age, duration of noise exposure, and equivalent noise-exposure level. For the machinist's mates, noise exposure in the main machinery room was assumed to begin at age 20, following 2 years of training. Retirement occurs at age 38 . No significant noise exposure was assumed outside working hours (while on active duty) or after retirement. Statistical death occurs at age 77 if the age of 40 is reached (17). Using ANSI S3.44-1996, we calculated predicted hearing threshold distributions for the machinist's mates for each year from age 18-77 years, given the assumed noise exposure conditions. The calculation of Navy and VA costs were based on these distributions of hearing loss.

Figure 1 shows the range ( $5^{\text {th }}$ and $95^{\text {th }}$ percentile) of predicted hearing thresholds associated with age and noise for machinist's mates at 18, 38, and 77 years of age. These ages correspond to the milestones of enlistment, retirement, and death, respectively. While some sailors are predicted to retain near-normal hearing for their entire lives, others will accrue considerable hearing loss (primarily age-related) by the age of 77 .

\section{Running the cost model on the example population}

We assumed that the machinist's mate enlists at age 18, receives 2 years of basic and advanced training, becomes a machinist's mate, accrues 6 years of noise exposure at an equivalent level of $93 \mathrm{~dB}(\mathrm{~A})$, retires after 20 years of service, and dies at age 77 . The probability distribution of susceptibility to noise is divided into discrete intervals with widths of 0.01 , from 0 (most susceptible) to 100 (least susceptible) [eg, $(0.00-0.01),(0.01-0.02), \ldots,(0.98-$

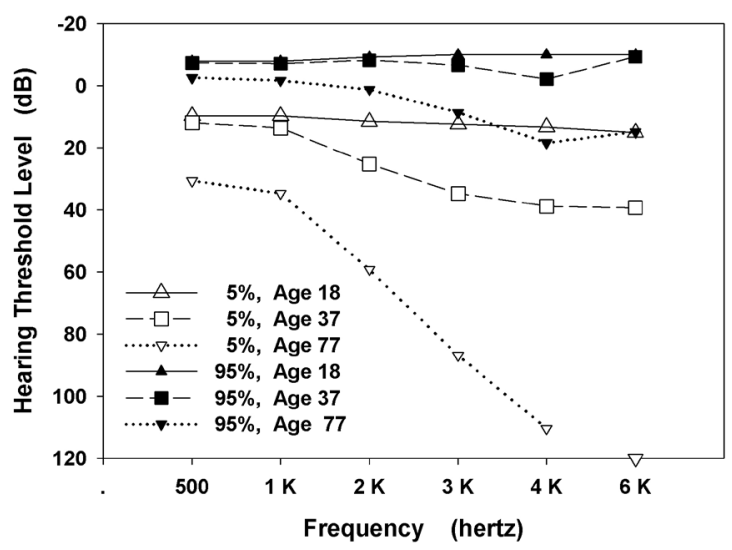

Figure 1. Range of projected hearing threshold levels of the example population of US Navy machinist's mates at enlistment (age 18), retirement (age 37), and statistical mortality (age 77). Closed and open symbols indicate $95^{\text {th }}$ and $5^{\text {th }}$ percentiles of the population, respectively. The separate inverted triangle at $6 \mathrm{kHz}$ indicates a threshold beyond measurable limits. 
0.99), (0.99-1.00)]. Using ANSI S3.44-1996, we calculated hearing-threshold levels for the centers of each probability interval (eg, 0.005 for the probability interval $0.00-0.01$ ) for each year from age 18-77 years, according to the noise exposure pattern described previously.

As a hypothetical example, let us take a male sailor who represents the most susceptible probability interval (ie, $0.00-0.01$ ). For the first four years, the only costs that accrue for this sailor are the fixed Navy HCP overhead (US\$12.21 annually) and the cost of annual monitoring audiometry with no STS (US\$68.52 annually). By the fifth year, the sailor's hearing thresholds, according to ANSI S3.44-1996, have deteriorated to the point that there is a small $(15.7 \%)$ probability that he will be issued a hearing aid $(\operatorname{cost}=0.157 \times$ US $\$ 440.03$ $=$ US\$69.18). This cost is added to the overhead and annual monitoring audiometry costs for that year. In year six, the sailor experiences an STS for the first time. Due to the follow-up associated with the STS (described previously), the cost of monitoring audiometry for that year is US\$111.46. The probability of receiving a hearing aid increases slightly as well. Both of these events add to the fixed annual HCP cost. In year seven, the probability of being issued a hearing aid increases further, but the cost of monitoring audiometry returns to US\$68.52 because there is no STS that year. Costs accrue in this manner until retirement. At that point, a one-time cost of US $\$ 110.00$ for the retirement audio $\mathrm{C} \& \mathrm{P}$ exam is incurred and the sailor (now a veteran) is almost certainly wearing a hearing aid. He is found to have service-connected hearing loss with a $0 \%$ percent disability. For the first sixteen years of retirement, the only VA costs are those associated with overhead and the maintenance of the hearing aid. By the $17^{\text {th }}$ year of retirement, the veteran's hearing loss has reached the

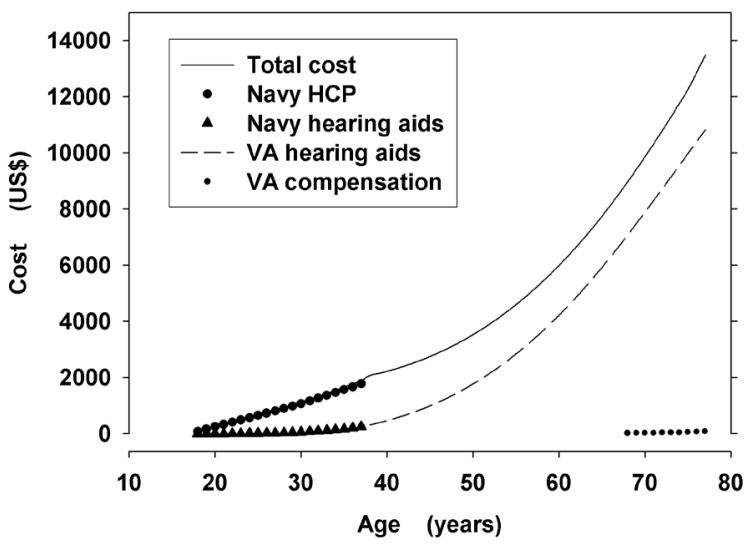

Figure 2. Average projected cumulative noise-induced hearing loss (NIHL)-related costs as a function of age for a US Navy machinist's mate. Veterans Administration (VA) compensation cost is low, only rising to US\$10 at age 67 , and to US\$84 at the end of statistical life. [HCP = hearing conservation program.]
$10 \%$ disability level, and he begins to receive disability compensation. Over the next 23 years, the percent disability (along with the associated cost of compensation) rises from $10-50 \%$. At the time of death, the cumulative NIHL-related cost over the sailor-veteran's lifespan is US\$64 172.39.

Costs are calculated the same way for all probability intervals and range from a high of US\$64 172.39 for the interval $(0.00-0.01)$ to a low of US\$862.34 for the interval (0.99-1.00). The average, or expected, cost is equal to the sum of the costs for each probability interval divided by 100 . This cost (ie, the total expected NIHLrelated cost over a sailor's lifespan) is US\$13 471 . Figure 2 shows the accumulation of expected NIHLrelated cost as a function of age.

\section{Sensitivity analysis}

Of interest to users of cost models is how the expected cost changes if inputs to the model change. We examined the effects on expected cost of changing the duration of noise exposure and equivalent noise-exposure level of the machinist's mates. To do this, we ran model computations in MATLAB for equivalent noise-exposure levels ranging from $85-100 \mathrm{~dB}(\mathrm{~A})$ in $1-\mathrm{dB}$ steps, for noise exposure durations ranging from $0-12$ years in 1-year steps. These ranges in noise level and duration encompass likely lower and upper bounds for potential machinist's mate exposure. Figure 3 shows the expected cost as a function of equivalent noise-exposure level for three representative durations: 3, 6, and 12 years. These durations correspond to the "typical" duration (ie, 6 years), and half and twice the "typical" duration. The nominal case of 6 years of exposure to an equivalent level of $93 \mathrm{~dB}(\mathrm{~A})$ is marked with an cross on the graph for reference.

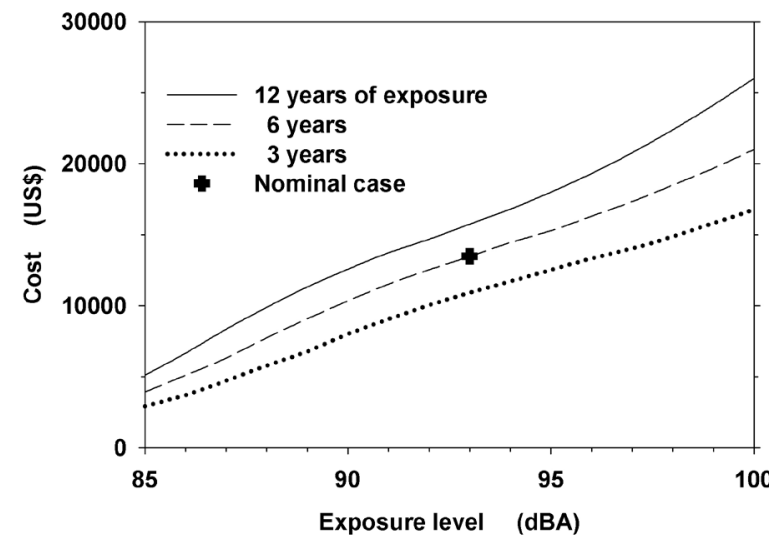

Figure 3. Average projected lifetime NIHL-related cost of a US Navy machinist's mate, as a function of normalized noise exposure level. The three lines represent 12,6 , and 3 years of noise exposure (ordered from top to bottom). The nominal case ( 6 years of exposure at $93 \mathrm{dBA}$ ) is marked with a cross. 


\section{Results}

As expected, figure 3 shows that the economic cost of NIHL is a monotonically increasing function of both noise-exposure level and duration. Between 85-100 $\mathrm{dB}(\mathrm{A})$, cost is a roughly linear function of exposure level for all exposure durations; between 3-12 years of exposure, cost is less than proportional to exposure time. Moreover, figure 3 reveals that cost rises more rapidly as years of exposure increase. This is shown by the greater divergence of costs for 3,6 , and 12 years of exposure at $100 \mathrm{~dB}(\mathrm{~A})$ than at $85 \mathrm{~dB}(\mathrm{~A})$, primarily because of the large effect of the small number of VAcompensable cases.

Our nominal noise exposure case [93 dB(A) for 6 years; shown by the cross on the graph] yielded total expected NIHL-related costs of US\$13 472 over the lifetime of a US Navy machinist's mate. The relative effects of exposure level and years of exposure on cost can be assessed by changing each variable by a fixed percentage. Starting with the nominal case, a decrease of $50 \%$ [ie, $10 \times \log (0.5)]$ in exposure level [from $93 \mathrm{~dB}(\mathrm{~A})$ to $90 \mathrm{~dB}(\mathrm{~A})$ ] or exposure duration (from 6 to 3 years) would yield cost savings of approximately 23 and 19\%, respectively. Conversely, a $50 \%$ increase in exposure level [ie, $10 \times \log (1.5)$ from $93 \mathrm{~dB}(\mathrm{~A})$ to $95 \mathrm{~dB}(\mathrm{~A})$ ] or years of exposure (from 6 to 9 years) would yield cost increases of approximately 14 and $11 \%$ respectively.

\section{Discussion}

\section{Interpretation of findings}

From the sensitivity analysis, we concluded that a reduction in noise level would be somewhat more costeffective than the same percentage reduction in years of exposure. Information generated by the model could be analyzed further to pinpoint the portion of the population that generates the greater share of costs. For example, in the case of machinist's mates, $22 \%$ of the population generates $50 \%$ of the costs. Knowing which portion of the population generates the most costs, and at what point in their careers, could allow for more strategic targeting of hearing-conservation approaches.

\section{Limitations}

Our economic model of NIHL was created with a single example population in mind; it is not immediately generalizable to other populations at present. Noise exposure data, cost data, assumptions, rates, and probabilities must be reassessed for each population, and updated and refined at regular intervals to keep the model current.
At this time, we are able to estimate the predicted savings in government-borne NIHL-related costs that would result from a decrease in noise-exposure level or years of exposure for machinist's mates. Importantly, however, we cannot yet compare those savings against the costs of the engineering or administrative controls necessary for their realization. Nevertheless, our model can provide the NIHL-related numbers to enter a costbenefit or trade-off exercise, once a specific engineering or administrative change is under consideration.

Due to a lack of data, we assumed no hazardous-noise exposure following retirement. However, this is almost certainly not the case for many veterans. In our model, as long as the veteran incurred an STS during active duty, his/her hearing loss is potentially compensable, even if most of the loss occurred subsequent to retirement. The NIHL-related cost calculated with our model could accordingly be seen as a lower bound of the true cost.

\section{Validity}

It is always desirable to validate a model by directly comparing its output to established data. Unfortunately, those data were not available to us because records and accounts are not centralized, nor are they maintained by the VA according to a veteran's military occupation.

\section{Adaptation of cost model to civilian populations}

Our cost model for NIHL could be adapted for use with civilian populations. First, using ANSI S3.44-1996, predicted hearing loss should be calculated at every age, for probability intervals of width $\geq 0.01$, from the average age at first employment to the age at which any NIHL-related benefits, such as workers' compensation, cease (eg, statistical mortality). For some occupations, exposure to impulse rather than steady-state noise is the norm. In that case, a predictive model of NIHL due to impulse or combined impulse/steady-state exposures should be incorporated in place of ANSI S3.44-1996.

Second, given the calculated hearing thresholds, NIHL-related costs must be calculated for each probability interval, for each age. To do this, costs of all NIHL-related items and the probability of their occurrence, must be known. The cost of tinnitus secondary to NIHL should be included if warranted. Naturally, the civilian cost structure will differ from the military one. A discussion of these differences is outside the scope of this article. Rates and probabilities (eg, rate of false positive STS) could be estimated from company records, or a bracketing approach could be used in which the costs of best- and worst-case scenarios are calculated. The cumulative costs in each probability interval could be averaged to determine the expected lifetime NIHL-related cost of an employee. The sensitivity of expected cost to various 
cost factors could be demonstrated by varying inputs to the model, as shown in figure 3 for the present case.

Future versions of this model could be used by system designers, acquisition personnel, occupational medicine specialists, industrial hygienists, and others to project the economic impact of adopting hearing conservation strategies such as altering personnel schedules or lowering noise levels.

\section{Acknowledgements}

The Office of Naval Research and the Defense Occupational Health Program funded this work. We thank Lynne Marshall for her continual programmatic support and thoughtful comments on this manuscript.

\section{References}

1. National Institute for Occupational Safety and Health (NIOSH). National Occupational Research Agenda (NORA) Priority Research Areas: Disease and injury (overview): Hearing loss [Internet]. US Department of Health and Human Services, Public Health Service, Centers for Disease Control and Prevention, NIOSH; 1996 [cited 20 August 2009]. Available from: http://www.cdc.gov/niosh/docs/96-115/ diseas.html\#hearings

2. Schneider E, Paoli P, Brun, E. Noise in figures. Luxembourg, Belgium: European Agency for Safety and Health at Work; 2005.

3. Nelson DI, Nelson RY, Concha-Barrientos M, Fingerhut M. The global burden of occupational noise-induced hearing loss. Am J Ind Med. 2005:48:446-58.

4. Moll Van Charante AW, Mulder PG. Perceptual acuity and the risk of industrial accidents. Am J Epidemiol. 1990;131:652-63.

5. Girard SA, Picard M, Davis AC, Simard M, Larocque R, Leroux T, et al. Multiple work-related accidents: tracing the role of hearing status and noise exposure. Occup Environ Med. 2009:66:319-24.

6. Price GR, Kalb JT, Garinther GR. Toward a measure of auditory handicap in the army. Ann Otol Rhinol Laryngol Suppl. 1989;98:42-52.

7. United States Department of Veterans Affairs. Veterans Benefit Administration Reports Home [Internet]. Washington (DC): United States Department of Veterans Affairs; 2009 [cited 20 August 2009]. Annual benefits reports FY 2005. Available from: http://www.vba.va.gov/REPORTS/abr/ historical/2005_abr.pdf

8. Bjorn VS, Albery CB, McKinley, RL. US Navy flight deck hearing protection use trends: survey results. Patuxent River (MD): Naval Air Warfare Center Aircraft Division; 2006. Report number NAWCADPAX/TR-2006/73.
9. Humes LE, Joellenbeck LM, Durch JS, editors. Noise and military service: implications for hearing loss and tinnitus. Washington (DC): Medical Follow-Up Agency, Institute of Medicine; 2005.

10. Sachs FZ, Weathersby PK, Marshall L, Tufts J. Model for estimating life-cycle costs associated with noise-induced hearing loss [Internet]. Groton (CT): Naval Submarine Medical Research Laboratory (NSMRL); 2007 [cited 24 January 2010]. NSMRL technical report 1248. Available from: http://www. dtic.mil/cgi-bin/GetTRDoc?AD=ADA461439\&Location= $\mathrm{U} 2 \&$ doc $=$ GetTRDoc.pdf.

11. American National Standards Institute. Determination of occupational noise exposure and estimation of noise-induced hearing impairment. New York (NY): American National Standards Institute; 1996. ANSI publication number S3.44 1996).

12. United States Department of Veterans Affairs. Fiscal year 2005 performance and accountability report [Internet]. Washington (DC): United States Department of Veterans Affairs, Office of Budget; c2005 November 15 [cited 16 September 2009]. Available from: http://www4.va.gov/budget/report.

13. United States Census Bureau. S1101: households and families [Internet]. Washington (DC): United States Census Bureau; 2008 [cited 16 September 2009]. Available from: http://factfinder.census.gov/servlet/STTable?_bm=y\&-geo $\mathrm{id}=01000 \mathrm{US} \&-q \mathrm{qr}$ name$=\mathrm{ACS}$ 2007_3YR_G00_S1101\&ds_name $=$ ACS_2007_3YR_G00

14. Tufts JB, Weathersby PK, Marshall L. Estimation of equivalent noise exposure level using hearing threshold levels of a population. Ear Hear. 2009:30(2):287-90.

15. Tufts JB, Weathersby PK, Marshall L, Sachs F. Model for estimating noise-induced hearing loss associated with occupational noise exposure in a specified US Navy population [Internet]. Groton (CT): Naval Submarine Medical Research Laboratory; 2007 [cited 25 January 2010]. Report number NSMRL 1247. Accessed from: http://archive.rubiconfoundation.org/dspace/bitstream/123456789/4989/1/ ADA461351.pdf

16. International Standards Organization. Acoustics determination of occupational noise exposure and estimation of noise-induced hearing impairment. Geneve (Switzerland): International Standards Organization; 1990. ISO publication number1990(E).

17. Hoyert DL, Kung H-C, Smith BL, editors. Deaths: preliminary cata for 2003. In: US Department of Health and Human Services, Centers for Disease Control and Prevention. National Vital Statistics Report [Internet]. Washington (DC): US Department of Health and Human Services, Centers for Disease Control and Prevention; 2005 [cited 19 September 2009]. Available from: http://www.cdc.gov/nchs/data/nvsr/nvsr53/nvsr53_15.pdf.

Received for publication: 6 October 2009 